\title{
Perceptual-center modeling is affected by including acoustic rate-of-change modulations
}

\author{
CHARLES ANDREW HARSIN \\ University of Arizona, Theson, Arizona
}

\begin{abstract}
This study investigated the acoustic correlates of perceptual centers (p-centers) in CV and VC syllables and developed an acoustic p-center model. In Part 1, listeners located syllables' p-centers by a method-of-adjustment procedure. The CV syllables contained the consonants $/ \check{\mathrm{s}} /, / \mathrm{r} /, / \mathrm{n} /, / \mathrm{t} /, / \mathrm{d} /, / \mathrm{k} /$, and $/ g /$; the VCs, the consonants $/ \breve{s} /, / r /$, and $/ n /$. The vowel in all syllables was $/ a /$ The results of this experiment replicated and extended previous findings regarding the effects of phonetic variation on $p$ centers. In Part 2, a digital signal processing procedure was used to acoustically model p-center perception. Each stimulus was passed through a six-band digital filter, and the outputs were processed to derive low-frequency modulation components. These components were weighted according to a perceived modulation magnitude function and recombined to create six psychoacoustic envelopes containing modulation energies from 3 to $47 \mathrm{~Hz}$. In this analysis, p-centers were found to be highly correlated with the time-weighted function of the rate-of-change in the psychoacoustic envelopes, multiplied by the psychoacoustic envelope magnitude increment. The results were interpreted as suggesting (1) the probable role of low-frequency energy modulations in p-center perception, and (2) the presence of perceptual processes that integrate multiple articulatory events into a single syllabic event.
\end{abstract}

The perceived rhythm of a series of acoustic tokens is affected by their acoustic structure. Tokens that differ acoustically must be placed in acoustic anisochrony, as measured from their onsets, to sound isochronous. For musical tones of equal duration, the departure from acoustic isochrony required depends on the tone's rise time (Gordon, 1987). For speech, changes in the duration or identity of different parts of syllables have differing effects on the perceived rhythm of series of alternating syllables (Marcus, 1981; Tuller \& Fowler, 1980). Allen (1972) and Donovan and Darwin (1979) have suggested that in natural speech as well, there is a rhythm determined by isochronously perceived stressed beats.

The relationship between speech acoustics and rhythm was first described by Morton, Marcus, and Frankish (1976). They defined the temporal locations in syllables that must be isochronous in order for repeated syllables to sound isochronous as the syllables' perceptual centers, or p-centers.

Simple acoustic correlates of $p$-centers have not been isolated. Syllable onset, vowel onset, final consonant onset,

Portions of this work were submitted in partial fulfillment of the requirements for the $\mathrm{PhD}$ in applied biopsychology at the University of New Orleans. The author wishes to thank James G. May, Emily Tobey, Jack Cullen, and Richard Schmidt. Special thanks are extended to Robert J. Porter, Jr., without whose support this work could not have been done. Thanks also to Kerry P. Green, who helped with the manuscript. This work was supported by a University of New Orleans Chancellor's Fellowship, by the University of New Orleans Department of Psychology, and by National Multipurpose Research and Training Center Grant DC-01409 from the National Institute on Deafness and Other Communication Disorders. Reprint requests should be sent to $\mathrm{C}$. A. Harsin, AHSC, Department of Neurology, Human Motor Control Laboratory, Tucson, AZ 85724 (e-mail: harsin@u.arizona.edu). and syllable peak energy have all been ruled out (Cooper, Whalen, \& Fowler, 1986). However, a few p-center models, of two different types, have been formulated. Phonetic modeling based on durations of phonetic segments in CV and CVC syllables shows initial consonant duration to be the primary phonetic determinant of p-center location. The duration of both the vowel and the final consonant affect p-center location to a smaller extent than does initial consonant duration (Marcus, 1981; PompinoMarschall, 1991). This model is consistent with the notion that the $\mathrm{C}-\mathrm{V}$ transition region is important in the determination of p-center location (Cooper et al., 1986; Fowler \& Tassinary, 1981; Smith \& Fowler, 1984).

Acoustic modeling based on amplitude envelope characteristics suggests that $p$-center locations are associated with the time course of acoustic energy changes within syllables (Howell, 1984, 1988; Pompino-Marschall, 1991; Scott \& Howell, 1992). Acoustic models suggest that both the energy distribution within the syllable (Howell, 1984, 1988; Pompino-Marschall, 1991; Scott \& Howell, 1992) and the syllable's spectral properties (Pompino-Marschall, 1991) influence p-center location. Tuller and Fowler (1981) found on the contrary that infinitely peak-clipping an utterance does not seem to affect the stress beat locations of the utterance's syllables. However, because of certain problems pointed out by Howell (1988), that study should probably not be taken as definitive.

One way to make a p-center model more psychologically plausible and more accurate might be to incorporate the energy modulation sensitivity of the human auditory system. The auditory system is sensitive to both the rate and magnitude of energy modulations within frequency bands, over a range of about $2-70 \mathrm{~Hz}$, with a maximum sensitivity at 3 or $4 \mathrm{~Hz}$ (Porter, 1986). These rates encom- 
pass the range of modulation rates that occur in speech. For example, Fastl (1987) examined running speech and found a range of modulation rate from 0.5 to $32 \mathrm{~Hz}$, with a maximum from approximately 3 to $8 \mathrm{~Hz}$.

Work by Chistovich and her colleagues (Chistovich et al., 1976) suggests that acoustic modulation sensitivity may be involved in speech perception. They found that modulations in the $30-\mathrm{Hz}$ range can be reliably labeled by Russian speakers as/r/-like. Lesogor (1977) found that this effect occurs independently of the modulated signal's frequency $(50-1000 \mathrm{~Hz})$ or type (a harmonic complex similar to a vowel vs. broadband noise). This " $/ \mathrm{r} /$ modulation" sensitivity has a bandpass characteristic, suggesting that modulation sensitivity may be organized as a set of tunable "filters" set to be maximally sensitive to specific ranges of modulation rate (Porter, 1986). Kay (1982), in an extensive review of human modulation sensitivity, concluded that modulation detection plays a vital part in speech perception. This is particularly the case in the recognition of syllables and phonetic transitions, both of which are especially germane to the issue of p-center perception.

Other research has shown that a model that exploits sensitivity for modulations within audio frequency bands can explain some phenomena in speech perception. Malinnikova, Ogorodnikova, and Stoljarova (1980) had human listeners segment several spoken passages into syllables. After obtaining human segmentation results, they segmented the same speech samples using a device that first divided the speech signal into CB-like audio frequency bands. They then filtered ("demodulated") each of these bands to detect energy modulations of 7, 25, and $75 \mathrm{~Hz}$. By marking when modulation magnitude within each CB surpassed a threshold value and then averaging the times of the markers across $C B$ regions, syllabic segmentation comparable to that obtained by human listeners was achieved. It seems that acoustic modulation sensitivity can be successfully exploited in modeling a type of speech perception that is closely related to p-center perception. Modulation sensitivity's involvement in perceptual tasks closely related to $\mathrm{p}$-center perception and its successful use in modeling syllabification raises the question of whether it plays a role in p-center perception. The purpose of the present study is to examine this question by testing a model incorporating modulation sensitivity against perceptual judgments of the p-center locations of spoken syllables varying in their acoustic structure and phonetic qualities.

\section{PART 1}

In Part 1, previous findings were systematically replicated and extended by the investigation of consonant duration, manner class, and voicing effects on p-centers in $\mathrm{CV}$ and VC syllables. The primary purpose was to ensure that the tokens used in the modeling section exhibited the same p-center characteristics as those found in other studies. A secondary rationale was to extend previous research with respect to the effects of final consonant duration on $p$-center location.

As for duration effects, lengthening the initial consonant in a CV syllable was predicted to increase p-center latency, with the nearly $1: 1$ relationship between consonant duration and $p$-center location that other research has shown (Cooper et al., 1986; Pompino-Marschall, 1991). The effect of lengthening the final consonant of a VC syllable should be to move the p-center toward the end of the syllable: such shifts are reported to be much smaller than those which occur when the initial consonant is altered (Marcus, 1981; Pompino-Marschall, 1991).

Changing the manner class (and thus the spectral properties) of either initial or final consonants was also predicted to change p-center location. Specifically, in CV syllables, nasals were predicted to have $p$-centers later than those for semi-vowels and semi-vowels were predicted to have p-centers later than those for fricatives, as Fowler found (1979). In accord with Fowler's finding, PompinoMarschall (1991) found that a CV beginning with a fricative (/ši/) had a p-center located closer to syllable onset than did a $\mathrm{CV}$ beginning with a nasal (/ma/), when consonant and vowel duration were controlled for. Also in accord with Fowler (1979), the p-center in CV syllables with a voiced consonant was predicted to be earlier than that in CV syllables with a nonvoiced consonant.

The effect of manner class and voicing on p-center location in VC syllables has not been investigated. If effects are present, we might expect either (1) that in accord with the p-center model of Pompino-Marschall (1991), VC syllables with energy present late in the consonant and with abrupt consonant offsets should have p-centers located farther from syllable onset than should other VC syllables, or (2) that the p-centers should be associated primarily with the onset characteristics of the vowels rather than with the consonant characteristics.

\section{Method}

\section{Subjects}

Eight native speakers of American English were screened as prospective subjects by requiring them to place the syllables "two" and "three" into acoustic isochrony with a 5-msec, $1000-\mathrm{Hz}$ click. On the basis of this task, 2 of the potential subjects were rejected, leaving 6 who were then paid to participate. One of the 2 was rejected because of random p-center adjustments and a self-report that the task was difficult; the other was rejected because of excessively long p-center adjustment times (more than 3 min per adjustment). In one section of the study, only 3 of the 6 subjects took part. None of the subjects reported a history of a speech or hearing disorder.

\section{Stimuli}

Three different sets of stimuli were used. The same male speaker produced all of the stimulus tokens at a moderate speaking rate in a small soundproof room. The tokens were low-pass filtered at $5 \mathrm{kHz}$ and digitized into a laboratory computer at a $10 \mathrm{-kHz}$ sampling rate with 12-bit resolution. For CV syllables, consonant duration was measured from the onset of acoustic energy to the $\mathrm{C}-\mathrm{V}$ boundary and vowel duration was measured from the $\mathrm{C}-\mathrm{V}$ boundary to the offset of acoustic energy. For VC syllables, vowel duration 
was measured from the onset of acoustic energy to the $\mathrm{C}-\mathrm{V}$ boundary and consonant duration was measured from the $\mathrm{C}-\mathrm{V}$ boundary to the offset of acoustic energy.

Stimulus Set 1: Nonstop CVs. The first stimulus set was created from three naturally produced CV syllables: /ša $/, / \mathrm{na} /$, and $/ \mathrm{ra} /$. The original consonant and vowel durations of the stimuli were as follows: $/$ ša $/$, consonant $=152 \mathrm{msec}$, vowel $=288 \mathrm{msec} ; / \mathrm{na} /$, consonant $=185 \mathrm{msec}$, vowel $=246 \mathrm{msec} ;$ and $/ \mathrm{ra} /$, consonant $=$ $178 \mathrm{msec}$, vowel $=255 \mathrm{msec}$. The consonant-vowel boundary was defined as the point where periodic vocalic waveforms appeared.

To test for effects of consonant duration on p-center location, each syllable in this stimulus set was edited to produce three variants with different durations. Portions of the syllables' consonants and vowels were deleted or duplicated and reinserted to create the durations required. The deleted or duplicated portions were taken from portions of the consonants that appeared as steady-state spectrogram areas. For the /ša/ and /na/ stimuli, the entire consonant appeared as steady state; for $/ \mathrm{ra}$ /, the first $160 \mathrm{msec}$ appeared as steady state. When portions of the stimuli were duplicated, the duplicated intervals were of between one and three pitch pulses. All cuts and splices were made at zero crossings.

Vowel duration was fixed at $280 \mathrm{msec}$, and consonants were edited to be 120,160 , and $200 \mathrm{msec}$. These procedures produced a set of nine stimuli (three consonants by three durations) that constituted the nonstop $C V$ set.

Stimulus Set 2: Stop CVs. Stimulus Set 2 was created from the four CV syllables $/ \mathrm{ta} /, / \mathrm{da} /, / \mathrm{ka} /$, and $/ \mathrm{ga} /$. The original consonant and vowel durations for these stimuli were as follows: /ta/, consonant $=80 \mathrm{msec}$, vowel $=360 \mathrm{msec} ; / \mathrm{da} /$, consonant $=80 \mathrm{msec}$, vowel $=352 \mathrm{msec} ; / \mathrm{ka} /$, consonant $=78 \mathrm{msec}$, vowel $=360 \mathrm{msec}$; and $/ \mathrm{ga} /$, consonant $=80 \mathrm{msec}$, vowel $=336 \mathrm{msec}$. For the unvoiced tokens, the $\mathrm{C}-\mathrm{V}$ boundary was defined as the appearance of the first periodic vocalic waveform. For the voiced tokens, the $C-V$ boundary was defined as the point where transitions ended and the vowel formant pattern appeared stable. The consonants were not edited in these stimuli, but vowels were edited as described previously to make the total duration of each of these syllables the same as that of the short syllables of the nonstop CVs (i.e., $400 \mathrm{msec}$ ). For the syllables $/ \mathrm{ta} /, / \mathrm{da} /$, and $/ \mathrm{ga} /$, the consonant duration was $80 \mathrm{msec}$ and the vowel duration was $320 \mathrm{msec}$. For the syllable $/ \mathbf{k a} /$, the consonant duration was $78 \mathrm{msec}$ and the vowel duration was $322 \mathrm{msec}$. This stimulus set, consisting of four stimuli, will be called the stop CV set.

Stimulus Set 3: VCs. Stimulus Set 3 was created from the three syllables/aš/, /an/, and /ar/. The original consonant and vowel durations for these stimuli were as follows: $/ \mathrm{as} /$, consonant $=150 \mathrm{msec}$, vowel $=249 \mathrm{msec} ; /$ an $/$, consonant $=178 \mathrm{msec}$, vowel $=229 \mathrm{msec}$; and $/ \mathrm{ar} /$, consonant $=196 \mathrm{msec}$, vowel $=252 \mathrm{msec}$. The $\mathrm{C}-\mathrm{V}$ boundary was defined as the point where steady formants for $/ \mathrm{r} /$ or $/ \mathrm{n} /$, or noise for $/ \check{s} /$, appeared. As in the nonstop CVs, the vowel durations were edited to $280 \mathrm{msec}$, and consonants were edited to be 120,160 , and $200 \mathrm{msec}$. These procedures produced a set of nine stimuli (three consonants by three durations), the $V C$ set.

\section{Procedure}

Listeners used a method of adjustment procedure to place the test syllables of each set into acoustic isochrony with a series of $5 \mathrm{msec}$, $1000-\mathrm{Hz}$ square-wave pulses (clicks) (cf. Pompino-Marschall, 1991). The stimuli were presented at a comfortable listening level, as adjusted by the subjects, monaurally $(\mathrm{R})$ over Telephonics TDH$49 \mathrm{P}$ headphones in a sound-shielded room. For each trial, a repeating, digitized loop, consisting of two fixed clicks and a movable test syllable, was presented to the listener by computer. The loop consisted of a 2 -sec interval. The clicks occurred at the beginning of the interval (the 0 -msec point) and $1 / 3$ of the way through the interval (the 667-msec point). At the beginning of each trial, the onset of the test syllable was placed, randomly, within $25 \mathrm{msec}( \pm)$ of the point that was $2 / 3$ of the way through the interval (the 1,334 -msec point). On each trial, the subject moved the test syllables relative to the clicks by pressing designated keys on a computer keyboard. Steps of $\pm 10, \pm 25$, and $\pm 50 \mathrm{msec}$ were available. ${ }^{1}$ Listeners adjusted the test syllable until the series of clicks and test syllable sounded isochronous. Between adjustments, the series of clicks and test syllable continued to play repeatedly, and subjects were allowed to take as much time as they wished to place the test syllable and the clicks into perceptual isochrony.

Each subject decided the p-center location for each stimulus, in each set, a total of 20 times. The order of stimuli within a session was random within blocks containing balanced subsets of the stimuli from the stimulus set. Listeners made the adjustments for all stimuli within a stimulus set before proceeding to another set. Half the subjects heard the nonstop $\mathrm{CV}$ set first: the other half heard the VC set first. Because the stop CV stimulus set was added to the study after subjects began running the other sets, all subjects heard the stop CV set last.

Total times to complete each stimulus set were approximately 3 , 1.5 , and $3 \mathrm{~h}$ for the nonstop CV set, the stop CV set, and the VC set, respectively. These total times were distributed over 4-5 days, in sessions of 30-60 min each, according to subjects' availability.

\section{Results}

\section{Nonstop CVs}

The data were analyzed in a two-way, within-subjects analysis of variance (ANOVA). The dependent variable was the obtained $p$-center for each stimulus: the unit of analysis was each subject's mean, adjusted p-center for the 20 trials for each stimulus. Independent variables were consonant manner class $(/ \check{\mathbf{s}} /, / \mathbf{n} /$, and $/ \mathbf{r} /)$ and consonant duration $(120,160$, or $200 \mathrm{msec}$ ). This yielded a 3 (consonants) $\times 3$ (durations) design.

Figure 1 and Table 1 indicate p-center locations as a function of consonant manner class and consonant duration. The findings accord with those of previous researchers and with this paper's predictions.

Consonant duration significantly affected $p$-center location $[F(2,10)=22.59, p<.001]$. P-center latency increased in a nearly 1:1 manner from syllabic onset with consonant duration. Post hoc tests showed a significant increase from the short- to the medium-duration conditions and from the medium- to the long-duration conditions. ${ }^{2}$ Consonant manner class also affected p-center location $[F(2,10)=14.27, p<.01]$. The significant main effect of consonant manner class is seen in the later (by about $24 \mathrm{msec}) \mathrm{p}$-centers for the $/ \mathrm{n} /$ syllables $(p<.05)$ as compared with the p-centers for the $/ \mathrm{r} /$ and $/ \check{\mathbf{s}} /$ syllables (which did not differ significantly). Consonant manner class and duration did not interact significantly $[F(4,20)=$ $2.20, p>.1]$.

\section{Stop CVs}

These data were analyzed in a two-way, within-subjects ANOVA. The dependent variable was the obtained $\mathrm{p}$ center for each stimulus; the independent variables were consonant voicing (voiced/voiceless) and consonant place of articulation (alveolar or velar). This yielded a 2 (voicing) $\times 2$ (places of articulation) design.

The p-center locations for each of the four syllables are indicated in Table 2. The ANOVA revealed that the voiced members of this stimulus set had shorter mean p-center latencies (by about $25 \mathrm{msec}$ ) than did the un- 


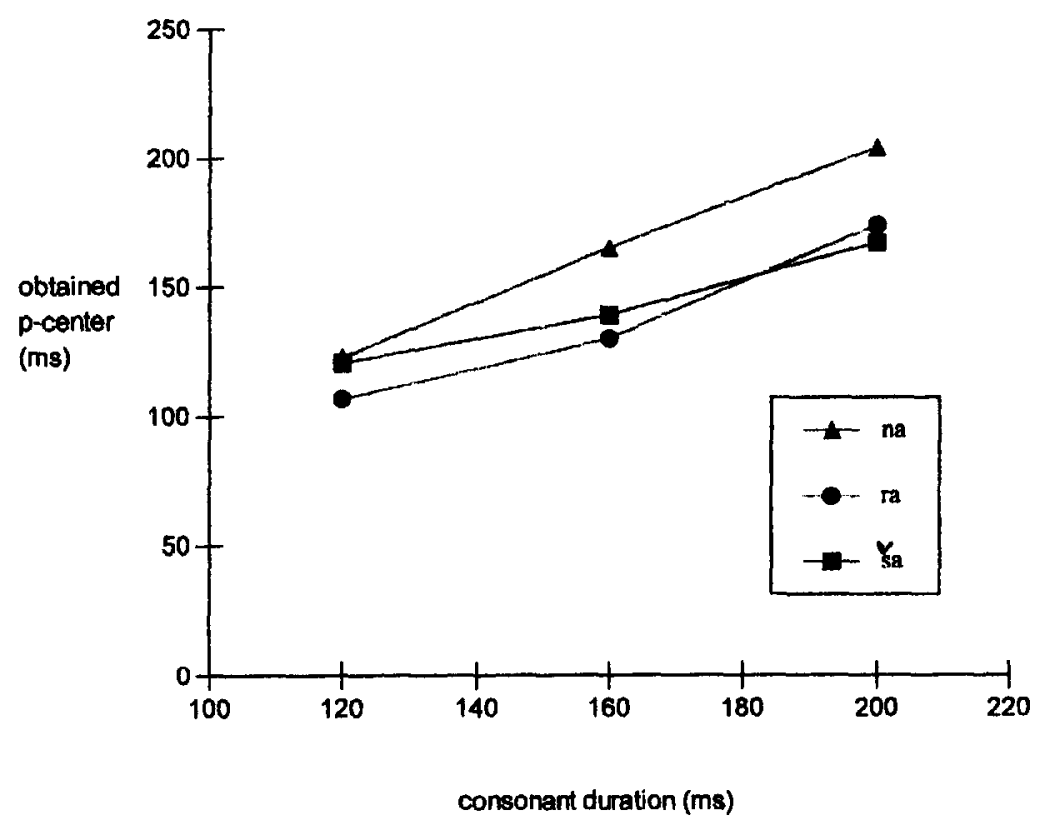

Figure 1. Obtained p-centers, nonstop CV stimulus set.

voiced members $[F(1,5)=27.41, p<.01]$, as predicted. Place of articulation did not affect p-center location $[F(1,5)=.25, p=.64]$. Voicing and place of articulation did not interact significantly $[F(1,5)=.27, p=.63]$.

\section{VCs}

Because of the likelihood that there might be very small or absent effects in the VC condition, the data for 3 subjects were collected and analyzed before deciding whether to collect data from the additional 3 subjects. These data were analyzed in a two-way, within-subjects ANOVA. The dependent variable was the obtained p-center for each stimulus; the units of analysis were each subject's mean adjusted $p$-center for the 20 trials for each stimulus. Independent variables were consonant manner class and consonant duration. This yielded a 3 (consonants) $\times 3$ (durations) design.

A summary of these data, by subject, is shown in Table 3. Contrary to predictions, consonant manner class

Table 1

Mean P-Center Locations (with Standard Deviations)

for Nonstop CV Stimulus Set (in Milliseconds; $n=6$ )

\begin{tabular}{|c|c|c|c|c|c|}
\hline \multirow[b]{3}{*}{ Stimulus } & \multirow{3}{*}{$\begin{array}{c}\text { Consonant } \\
\text { Duration } \\
\end{array}$} & \multicolumn{4}{|c|}{ P-Center Locations } \\
\hline & & \multicolumn{2}{|c|}{ By Duration } & \multicolumn{2}{|c|}{ By Stimulus } \\
\hline & & $M$ & $S D$ & $M$ & $S D$ \\
\hline \multirow[t]{3}{*}{$/ \check{\text { sa } /}$} & 120 & 121 & 11 & & \\
\hline & 160 & 139 & 27 & & \\
\hline & 200 & 167 & 32 & 142 & 24 \\
\hline \multirow[t]{3}{*}{$/ \mathbf{r a} /$} & 120 & 107 & 16 & & \\
\hline & 160 & 130 & 29 & & \\
\hline & 200 & 174 & 50 & 137 & 36 \\
\hline \multirow[t]{3}{*}{$/ \mathrm{na} /$} & 120 & 123 & 29 & & \\
\hline & 160 & 165 & 42 & & \\
\hline & 200 & 204 & 48 & 164 & 39 \\
\hline
\end{tabular}

Note-Consonant durations are given in milliseconds. did not significantly affect $\mathrm{p}$-center location in these stimuli $[F(2,4)=1.18, p=.40]$, nor did consonant duration $[F(2,4)=.25, p=.79]$. Consonant manner class and duration also did not interact significantly $[F(4,8)=$ $1.41, p=.32]$. Note that the absence of significance does not appear to be due to the small number of subjects (they are very much alike) or to an unusually high variance (the SDs are smaller or comparable to those for the nonstop CV set). Given the absence of even a small trend in the data, together with the suggestion in prior studies that effects would be small or absent, additional VC data were not collected.

\section{Discussion}

The clearest relationship between stimulus variables and p-center location found in past studies is a shift in pcenter location with a consonant duration variation in CV syllables. The present study also produced this result in the nonstop CV stimulus set, and the size of the p-center shift found here was comparable to that in previous studies (Cooper et al., 1986; Pompino-Marschall, 1991). For example, Pompino-Marschall found that each $40 \mathrm{msec}$ increase in consonant duration resulted in an approximately $37-\mathrm{msec}$ shift in p-center location away from syllable onset for synthetic /ma/ syllables. Our data from the nonstop $\mathrm{CV}$ set reveal a similar shift of p-center with consonant duration change: a 40 -msec increase in consonant duration resulted in an average $33-\mathrm{msec}$ shift in p-center away from the beginning of the syllable.

For the stop CV stimulus set, the earlier p-center for voiced as opposed to voiceless stops is consistent with previous findings by Fowler (1979). Voiced stops have acoustic energy, associated with onset of voicing, nearer to their onset, whereas voiceless stops do not. In this respect, the CVs with voiced stop consonants resemble the VCs, and 
Table 2

Mean P-Center Locations (With Standard Deviations)

for the Stop CV Stimulus Set (in Milliseconds; $n=6$ )

\begin{tabular}{|c|c|c|c|c|c|c|c|c|c|c|c|c|c|c|c|}
\hline \multicolumn{4}{|c|}{ Stimulus } & & & \multicolumn{4}{|c|}{ Stimulus } & & & \multicolumn{4}{|c|}{$\begin{array}{c}\text { Place of } \\
\text { Articulation }\end{array}$} \\
\hline \multicolumn{2}{|c|}{$/ \mathrm{ga} /$} & \multicolumn{2}{|c|}{$/ \mathrm{da} /$} & \multicolumn{2}{|c|}{ Voiced } & \multicolumn{2}{|c|}{$/ \mathrm{ka} /$} & \multicolumn{2}{|c|}{$/ \mathrm{ta} /$} & \multicolumn{2}{|c|}{ Voiceless } & \multicolumn{2}{|c|}{ Velar } & \multicolumn{2}{|c|}{ Alveolar } \\
\hline$M$ & $S D$ & $M$ & $S D$ & $M$ & $S D$ & $M$ & $S D$ & $M$ & $S D$ & $M$ & $S D$ & $M$ & $\overline{S D}$ & $M$ & $\overline{S D}$ \\
\hline 39 & 17 & 35 & 11 & 37 & 12 & 69 & 15 & 58 & 15 & 64 & 12 & 54 & 14 & 47 & 11 \\
\hline
\end{tabular}

the p-center locations found for those CVs are also similar to those of the VCs.

As in previous studies, manner class of initial consonant in the CV syllables significantly affected p-center (Fowler, 1979; Pompino-Marschall, 1991). The stops had the earliest p-centers of all of the CV stimuli. This observation can be extended by comparing the nonvoiced-stop $\mathrm{CVs}$ (which are most similar to the nonstop CVs both in psychoacoustic envelope and in p-center location) to the shortest duration nonstop CVs. The voiceless stop CVs have 80 - $\mathrm{msec}$ consonant durations $(78 \mathrm{msec}$, for $/ \mathrm{ka} /$ ); for the shortest nonstop CVs, consonant durations are $120 \mathrm{msec}$. The p-centers of the voiceless stop CVs are about 40-50 msec earlier than the p-centers of the nonstop CVs. Thus, in these stimuli, p-center location seems at least partially related to the consonant duration. However, duration is not the only factor, as is illustrated by the comparison of nonstop CVs with consonants of the same duration. For these CVs, there is a significant difference, across stimulus durations, of $24 \mathrm{msec}$ between the p-center location of the nasal CV $(/ \mathrm{na} /)$ at $164 \mathrm{msec}$ and the fricative and semivowel CVs (/ša/ and $/ \mathrm{ra} /$ ) at 143 and $137 \mathrm{msec}$, respectively. The difference in /ša/ and $/ \mathrm{ra} / \mathrm{p}$-center locations was not significant. These results also parallel Fowler (1979). For all but the shortest consonant duration, /na/ had a later $\mathrm{p}$-center than did the other two stimuli. Since consonant durations were the same in these stimuli, acoustic events within the consonant probably account for the p-center differences, possibly the different energy by frequency distributions between these consonants.

One difference between the findings of this experiment and earlier studies was the present study's absence of an effect for consonant variation in VC syllables. However, only one previous study varied VC final-consonant duration independently of the vowel (Pompino-Marschall, 1991). As previously noted, the results of that study were that final consonant duration effects were small and did not appear for all 40-msec increases in final consonant duration. Twenty percent of consonant duration increases did not result in a p-center shift. Moreover, the 2 subjects who participated in Pompino-Marschall's study were selected because of their consistent performance on a previous p-center adjustment task. Perhaps if more highly trained subjects had been used in the present study, small effects of final consonant duration would also have been obtained. However, the absence of any trend in the data does not lend much support to this possibility.

The results of Part 1, along with previous findings, show that p-center location is not determined by a syllable's durational aspects alone. Moreover, changes in p-center are independent of phonetic categorization (Cooper et al., 1986). Acoustic properties of the speech signal, such as its energy distribution (both in time and across critical bands), do seem to affect p-center location. These results suggest that psychoacoustic processing of spectrotemporal cues could underlie p-center perception in speech. The second part of this study consists of an attempt to demonstrate a connection between acoustic properties and p-center perception, using the tokens from Part 1.

\section{PART 2}

In Part 2, digital processing procedures were used in an attempt to broadly model some of the psychoacoustic processing that might be involved in $\mathrm{p}$-center perception.

Table 3

Individual and Group Mean P-Center Locations (With Standard Deviations) for VC Stimulus Set (in Milliseconds; $n=3$ )

\begin{tabular}{|c|c|c|c|c|c|c|c|c|c|c|c|}
\hline \multirow[b]{3}{*}{ Stimulus } & \multirow{3}{*}{$\begin{array}{c}\text { Consonant } \\
\text { Duration }\end{array}$} & \multicolumn{6}{|c|}{ Subject } & \multicolumn{4}{|c|}{ P-Center Locations } \\
\hline & & \multicolumn{2}{|c|}{1} & \multicolumn{2}{|c|}{2} & \multicolumn{2}{|c|}{3} & \multicolumn{2}{|c|}{ By Duration } & \multicolumn{2}{|c|}{ By Stimulus } \\
\hline & & $M$ & $S D$ & $M$ & $S D$ & $M$ & $S D$ & $M$ & $S D$ & $M$ & $S D$ \\
\hline \multirow[t]{3}{*}{ /aš/ } & 120 & 58 & 52 & 42 & 29 & 18 & 24 & 39 & 20 & & \\
\hline & 160 & 40 & 53 & 55 & 40 & 10 & 18 & 35 & 22 & & \\
\hline & 200 & 65 & 47 & 39 & 31 & 32 & 31 & 45 & 17 & 39 & 18 \\
\hline \multirow[t]{3}{*}{ /ar/ } & 120 & 51 & 36 & 59 & 78 & 13 & 23 & 41 & 25 & & \\
\hline & 160 & 47 & 40 & 50 & 82 & 17 & 39 & 38 & 18 & & \\
\hline & 200 & 48 & 33 & 38 & 42 & 15 & 29 & 33 & 17 & 38 & 18 \\
\hline \multirow[t]{3}{*}{ /an/ } & 120 & 61 & 42 & 39 & $4 I$ & 14 & 23 & 34 & 17 & & \\
\hline & 160 & 56 & 54 & 48 & 40 & 10 & 27 & 38 & 25 & & \\
\hline & 200 & 43 & 42 & 42 & 48 & 4 & 23 & 30 & 22 & 35 & 21 \\
\hline
\end{tabular}

Note-Consonant duration is given in milliseconds 
The components of the model were drawn from the successful modeling of Scott and Howell (1992) and PompinoMarschall (1991) and from the previously cited literature concerning the possible role of modulation processing in speech perception.

Existing $p$-center models suggest which acoustic characteristics might be associated with speech p-centers. Pompino-Marschall (1991) modeled p-centers with a method which suggests that acoustic modulations within audio frequency bands may affect p-center location. Similarly, Scott and Howell (1992) have presented a p-center model which suggests that, at least for some syllables, points of maximum acoustic energy rate-of-change are associated with p-centers. Their model also takes into consideration energy changes within different frequency bands. Additionally, speech processing techniques based on the psychoacoustic detection of energy modulations within critical-band audio frequency regions have yielded phonetic segmentation of syllables comparable to human segmentation (Malinnikova et al., 1980). The rates of the energy modulations detected with this method are the rates of articulations and energy modulations that are associated with speech rhythms (Fastl, 1983) and that might also be associated with p-centers. Part 2 is an attempt to develop an account of $p$-centers based on rates of acoustic energy change within audio frequency bands. The model developed here differs from one or both of the previous pcenter models mentioned in that a single model is used for all syllable types, acoustic changes throughout the syllable are incorporated into the model, and a perceived acoustic modulation magnitude weighting function is applied.

\section{Signal Processing}

First, the speech signal was low-pass filtered at $5 \mathrm{kHz}$ with an analog filter and was digitally sampled at $10 \mathrm{kHz}$. This provided a frequency range covering most of the important information in the speech signal.

Next, the signal was digitally band-pass filtered with second-order Butterworth filters, with rolloffs of $3 \mathrm{~dB} /$ octave. The band-pass filter ranges corresponded to two critical bandwidths, allowing subsequent within-frequencyband loudness scaling and envelope extraction to be performed. These bandwidths were chosen for several reasons: (1) to provide sufficient narrowness to reflect speechrelevant changes in formants, (2) to provide enough filters to cover the range of expected spectral variations in the signals, and (3) to make the process computationally practical. These bandwidths are similar to those used by Scott and Howell (1992) in their p-center model.

After band-pass filtering, an envelope was extracted by replacing each value in the signal with its absolute value. This rectified signal was then digitally low-pass filtered at $100 \mathrm{~Hz}$ with a third-order Butterworth filter, downsampled to a rate of $400 \mathrm{~Hz}$, and again digitally low-pass filtered at $100 \mathrm{~Hz}$ with a third-order Butterworth filter to eliminate any discontinuities in the signal created by downsampling.

The signal was then scaled for loudness by raising each value to the 0.3 power to reflect the power law relationship between physical intensity and loudness. In the au- ditory system, this process may be thought of as taking place within critical bands; it was applied in the present model to each of the individual frequency envelopes. The process resulted in relative loudness that was comparable across the audio frequency bands. The process was similar to that used by Pompino-Marschall (1991) as well as that employed by Malinnikova et al. (1980) and Suchowerskyj (1977).

Next, 512 zeroes were added to the beginning of the signal to make subsequent analysis possible. This zero padding was necessary so that the signal would be analyzed from the beginning, rather than having the entire initial part of the signal analyzed simultaneously. Otherwise, changes occurring over the initial part of the signal could not be detected. To determine the modulation rate components of the envelope, 512-point fast Fourier transforms (FFTs) were taken of the signal, yielding a modulation spectrum for the modulation range of $1.5-200 \mathrm{~Hz}$, in $0.79-\mathrm{Hz}$ steps. The FFTs were taken sequentially from the beginning to the end of the signal. Because the beginning of the signal was offset by 512 zero points, the first FFT was of a null signal. A rectangular window was used to calculate the FFTs. The window was moved 4 points $(10 \mathrm{msec})$ into the signal for each successive FFT. The total number of FFTs taken for the 22 stimuli ranged from 40 to 48 , depending on stimulus duration.

A power spectrum was then extracted for each FFT. The values in the power spectrum were divided into four modulation rate ranges, with center rates (bandwidths) of 4.3 (2.3), 9.0 (5.5), 18.4 (10.9), and 36.3 (23.4) Hz. Because of their small magnitude, power spectrum values corresponding to modulation rates of more than $47.7 \mathrm{~Hz}$ were not included in the analysis. Each range of modulation components was then weighted according to a perceived modulation magnitude function (Fastl, 1987). Weights for the 4.3-, 9.0-, 18.4-, and $36.3-\mathrm{Hz}$ energy modulation regions were $1.00,0.80,0.45$, and 0.20 , respectively. This weighting thus provided a low-modulation frequency "gain" corresponding to the greater perceptual weight given to modulations in the $4-\mathrm{Hz}$ region.

The weighted modulation components were then recombined into a modulation energy psychoacoustic envelope. The psychoacoustic envelope may be thought of as a crude representation of the speech signal in a particular audio frequency band after it has been scaled for loudness, low-pass filtered, and demodulated to reveal low-frequency modulation components in the perceptually relevant range of approximately $2-50 \mathrm{~Hz}$. These processing steps are broadly represented in Figure 2.

To analytically recover the rates of change in the psychoacoustic envelope, the first derivative of each envelope was calculated. Peaks in the first derivative function indicate points of locally maximum increase of the psychoacoustic envelope. The psychoacoustic envelopes for the different frequency bands of the different stimuli typically have peaks corresponding to the consonant onset and to the onset of the vowel segment. Although not every single psychoacoustic envelope of every stimulus has both of these peaks, most do, and both peaks 


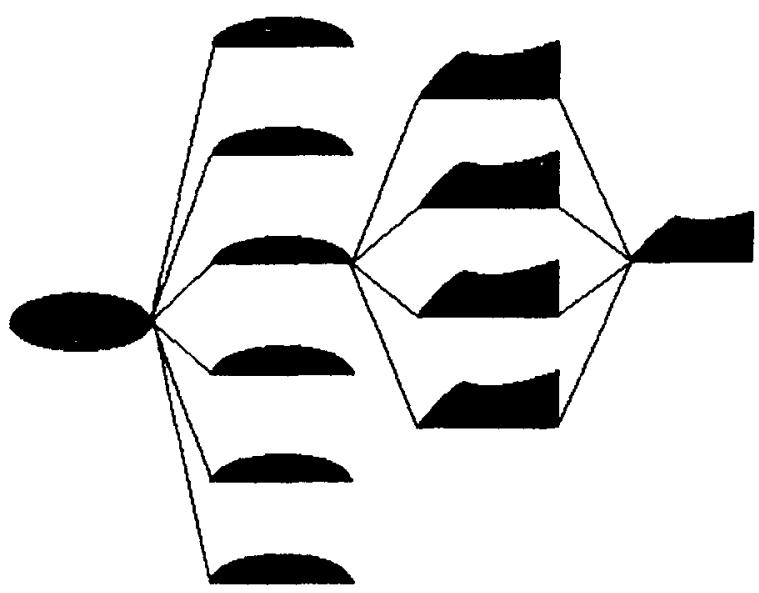

Figure 2. Schematic representation of signal processing: the stimulus (1) is divided into six rectified bandpass components (2); from each bandpass component four low-frequency modulation envelopes are extracted (3); each bandpass component's modulation envelope is weighted according to a perceived modulation magnitude function, and then recombined into a psychoacoustic envelope (4). Each stimulus yields six psychoacoustic envelopes, one corresponding to each bandpass component.

occur in at least some of the psychoacoustic envelopes for every stimulus. The peaks in the first derivative plots of the psychoacoustic envelopes (henceforth psychoacoustic envelope velocity peaks or velocity peaks) correspond to these segmentation points. It is the temporal distribution and magnitude of these psychoacoustic envelope velocity peaks that might play a role in p-center perception.

\section{Calculating P-Centers}

To calculate p-center locations from the stimuli, psychoacoustic envelope points of maximum rate of change were mathematically combined. Each of the six audio frequency bands of each stimulus can contain multiple psychoacoustic envelope velocity peaks. If each peak for a particular stimulus is numbered, from earliest to latest, and from lowest frequency band to highest, then the six frequency bands contain $n$ peaks occurring at times $T_{1}-\mathrm{T}_{n}$ whose corresponding velocity peaks' magnitudes are $V_{1}-V_{n}$. Each such peak also has an associated psychoacoustic envelope magnitude increment, $M_{1}-M_{n}$. Each of these increments is the amount of change in psychoacoustic envelope magnitude since the last velocity peak, for that envelope. This model will be called the per band velocity model, or BVM. Its formula is

$$
\frac{\sum_{t_{1}}^{n}\left(V_{t} \times T_{t}\right)}{\sum_{t_{1}}^{n}\left(V_{t}\right)} .
$$

The correlation coefficient for the comparison of obtained p-centers and those obtained with the BVM was .96 ( $p<$ .01 ). The regression equation was $y=17.9+1.33 x$.

Inspection of psychoacoustic envelope magnitudes and velocities and their associated p-centers suggested that considering psychoacoustic envelope magnitude changes might enhance the accuracy of $\mathrm{p}$-center prediction. For example, the BVM consistently predicted p-centers in the nonstop CV syllables to be too close to stimulus onset, whereas it predicted the p-centers of the VC stimuli to be too far from stimulus onset. This pattern suggests that, in the nonstop CV syllables, not enough weight was being given to the velocity peaks associated with the large increase in psychoacoustic envelope magnitude of the vowel onset, whereas in the VC syllables, too much weight was being given to velocity peaks associated with small psychoacoustic envelope magnitude "ripples" occurring after the vowel onset. Therefore, p-centers were also calculated on the basis of velocity peaks weighted by psychoacoustic envelope magnitude. This model will be called the per band magnitude-weighted velocity model, or the "BMVM." Its formula is

$$
\frac{\sum_{t_{1}}^{n}\left(M_{t} \times V_{t} \times T_{t}\right)}{\sum_{t_{1}}^{n}\left(M_{t} \times V_{t}\right)} .
$$

The correlation coefficient for the comparison of obtained $p$-centers and those obtained with the BMVM was $.99(p<.01)$. The regression equation was $\mathrm{y}=9.3+1.12 x$.

In order to systematically separate independent effects of psychoacoustic envelope magnitude increments and magnitudes' velocity peaks in finding p-center location in the BMVM model, p-centers were also calculated from psychoacoustic envelope magnitude increments alone. This model will be called the per band magnitude model, or BMM. Its formula is

$$
\frac{\sum_{t_{1}}^{n}\left(M_{t} \times T_{t}\right)}{\sum_{t_{1}}^{n}\left(M_{t}\right)} .
$$

The correlation coefficient for the comparison of obtained p-centers and those obtained with the BMM was .91 ( $p<$ .01 ). The regression equation was $y=37.7+1.15 x$.

Figure 3 shows the predictions of all models as a function of the p-center locations obtained by the subjects. Of the models examined, the BMVM most accurately modeled p-center locations. Its regression equation indicates a more nearly $1: 1$ relationship between its predictions and the obtained p-center than was obtained with the other models, and also a smaller constant difference between the predicted and obtained p-centers. This model predicted $\mathrm{p}$-center location better than did models based on velocity peaks or magnitude increments alone. For comparison, the correlation coefficient (for the CV syl- 


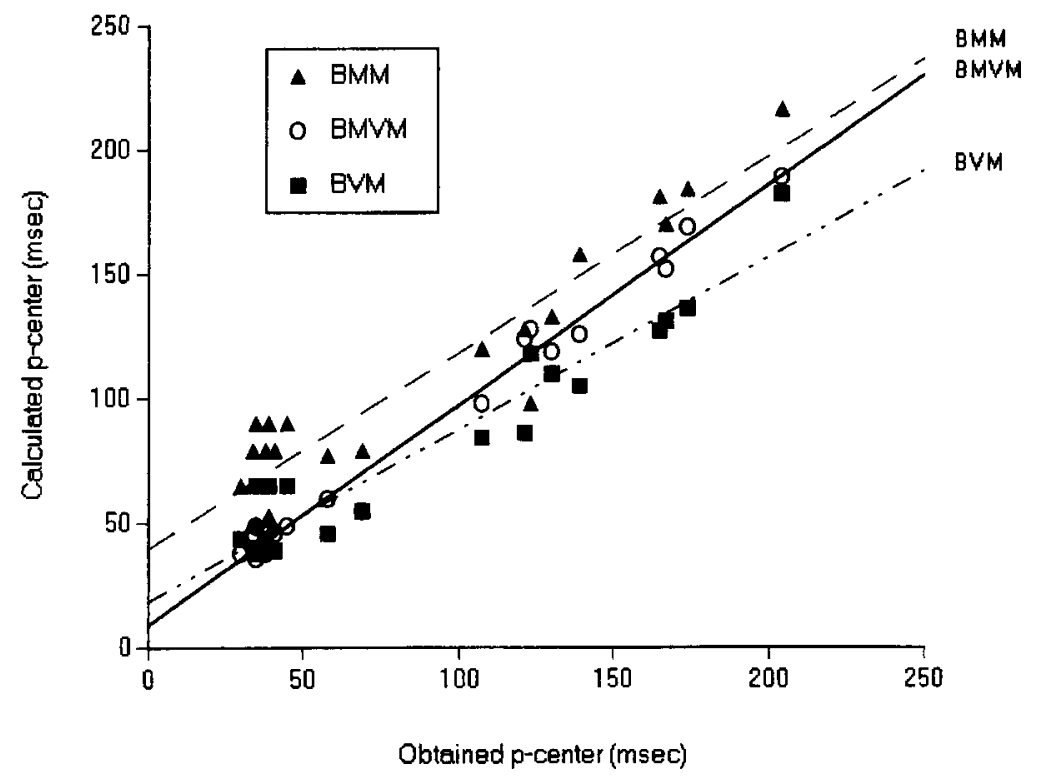

Figure 3. Calculated p-center as a function of obtained p-center, all models. Each symbol represents one stimulus syllable $(N=22)$.

lables) for the obtained p-center and consonant duration was .87 .

\section{Discussion}

The results of this analysis show that p-centers can be modeled by a time-weighted combination of psychoacoustic envelope magnitude increment and velocity. The observed role of velocity is consistent with that in prior studies suggesting that peaks in energy rates of change are associated with p-centers. In some of those studies, energy rates of change were explicitly incorporated in p-center models for speech and non-speech stimuli (Gordon, 1987; Scott \& Howell, 1992).

Pompino-Marschall's (1991) p-center model also lends some support to the notion that energy magnitude increments at velocity peaks might be perceptually associated with p-centers. Although he names energy modulation magnitude increments as the important events in calculating p-centers, Pompino-Marschall finds it necessary to use the points at which energy reaches $40 \%$ of a local maximum to perform p-center calculations. This $40 \%$ point approximates the point at which the velocity peak might be expected to occur, so his model may be said to predict p-centers from two parameters that approximate the psychoacoustic envelope magnitude increments and the velocity peaks used in the present model.

The present psychoacoustic approach to p-center modeling helps explain some results obtained with phonetic manipulations in Part 1. As previously noted, each psychoacoustic envelope contains one large velocity peak. This peak is associated with acoustic events at vowel onset in most of the stimuli. For example, this peak velocity appears to be associated with the $\mathrm{C}-\mathrm{V}$ transition in both the nonstop CVs and the voiceless stop CVs. Depending on the syllable, the peak occurs about $80-160 \mathrm{msec}$ after the syllabic onset. Similarly, in the voiced-stop CV stimuli, the velocity peak is associated with the consonant release and the formant transitions at the beginning of the syllable. Examination of p-center data reveals that p-centers for the nonstop CVs and the unvoiced-stop CVs occur about halfway between the consonant onset and the vowel onset, whereas the p-center of the voiced-stop CVs occur about midway between the burst and the end of the formant transitions. In all cases, then, the p-center appears particularly influenced by the velocity peaks associated with transitional regions. The pattern of psychoacoustic envelope velocity peaks for the different syllables thus appears to capture the spectrotemporal differences responsible for the syllables' different p-center locations.

The psychoacoustic envelopes also capture spectral differences among the nonstop CVs that might account for the $\mathrm{p}$-center of /na/ occurring at a significantly later point in time than does the p-center of either $/ \mathrm{sa} /$ or $/ \mathrm{ra} /$. The fact that $/ \mathrm{n} /$ has more energy in lower frequency regions (owing to nasal resonance) than does $/ \check{\mathrm{s}} / \mathrm{or} / \mathrm{r} /$ is reflected in the psychoacoustic envelopes of the /na/ stimuli displaying velocity peaks only in the three lower frequency bands. The per band processing of the model thus weights the consonantal portion of /na/more lightly than the consonantal portions of $/ \check{\mathrm{s}}$ / or $/ \mathrm{ra} /$, because it contains fewer consonantal velocity peaks: consequently, the p-center of /na/ is closer to the vowel-onset velocity peak than are the p-centers of $/$ ša $/$ or $/ \mathrm{ra} /$. Because it is the per band processing of the model that enables it to correctly calculate the different $p$-centers of the nonstop CV stimuli, these results suggest that the auditory system extracts and analyzes modulation information within different audio frequency regions before bringing the results together to 
yield a perceived temporal structure. Except for the voiced-stop CVs, all the stimuli contain (in all or most of their frequency bands) a psychoacoustic envelope velocity peak associated with consonant onset. Because this processing technique produces clear markers for consonant onset and for $\mathrm{CV}$ transitions, it nicely captures the phonetic variable most strongly associated with $\mathrm{p}$-center location: initial consonant duration. Changing initial consonant duration changes the time between the consonantonset and CV-transition velocity peaks and thus changes the calculated $p$-center in ways that parallel changes in listeners' $p$-center judgments.

The present model of p-center perception exploits human acoustic modulation sensitivity to accurately predict the p-centers of speech tokens of various acoustic and phonetic structures. It provides a step toward a general model of p-center perception and may also shed light on the perceptual processes involved in human perception of p-centers and of rhythm.

\section{REFERENCES}

ALLEN, G. (1972). The location of rhythmic stress beats in English: An experimental study, I. Language \& Speech, 15, 72-100.

Chistovich, L. A., Ventsov, A. V., Granstrem, M. P., Zhukov, S. Y., Zhukova, M. C., Karnitskaya, E. G., Kozhevnikov, V. A., Lisenko, D. M., Lyublinskaya, V. N., Mushnnikov, V. N., Slepokurova, N. A., Fedorova, N. A., KhaAvel, R. K., Chistovich, I. A., \& Shuplyakov, V. S. (1976). Physiology of speech: Human speech perception (pp. 125-131). Leningrad: Nauka.

COOPER, A. M., Whalen, D. H., \& Fowler, C. A. (1986). P-centers are unaffected by phonetic categorization. Perception \& Psychophysics, 39, 187-196.

Donovan, A., \& Darwin, C. (1979). The perceived rhythm of speech. In Proceedings of the Ninth International Congress of Phonetic S $\mathrm{Ci}$ ences (Vol. 2, pp. 268-274). Copenhagen: University of Copenhagen, Institute of Phonetics.

FASTL, H. (1983). Fluctuation strength of modulated tones and broadband noise. In R. Kline \& R. Hartmann (Eds.), Hearing-physiological bases and psychophysics (pp. 1-5). New York: Springer-Verlag.

FASTL, H. (1987). A background noise for speech audiometry. Audiological Acoustics, 26, 2-13.

FowlER, C. A. (1979). "Perceptual centers" in speech production and perception. Perception \& Psychophysics, 25, 375-388.

Fowler, C. A., \& TASSINARY, L. (1981). Natural measurement criteria for speech: The anisochrony illusion. In J. Long \& A. D. Baddeley (Eds.), Attention and performance $I X$ (pp. 521-535). Hillsdale, NJ: Erlbaum.

Gordon, J. W. (1987). The perceptual attack time of musical tones. Journal of the Acoustical Society of America, 82, 88-105.

HOWELL, P. (1984). An acoustic determinant of perceived and produced anisochrony. In M. P. R, van den Broecke \& A. Cohen (Eds.), Proceedings of the 10th International Congress of Phonetic Sciences (pp. 429-433). Dordrecht: Foris.

Howell, P. (1988). Prediction of P-center location from the distribution of energy in the amplitude envelope: I. Perception \& Psychophysics, 43, 90-93.

KAY, R. H. (1982). Hearing of modulation in sounds. Physiological Reviews, 62, 894-975.

LESOGOR, L. V. (1977). Determination of the permissible frequency difference during perception of the (r) pause. Fiziologiya Cheloveka, 3 , 85-88.

Mallinikova, T. G., Ogorodnikova, E. A., \& Stoljarova, E. I. (1980). Application of the amplitude irregularity detection for running speech segmentation. Fiziologiya Cheloveka, 66, 139-145.

MARCUS, S. M. (1981). Acoustic determinants of perceptual center (Pcenter) location. Perception \& Psychophysics, 30, 247-256.

Morton, J., Marcus, S. M., \& Frankish, C. R. (1976). Perceptual centers (P-centers). Psychological Review, 83, 405-408.

Pompino-Marschall, B. (1991). The syllable as a unit and the socalled p-center effect. Forschungberichte des Instituts für Phonetik und Sprachliche Kommunikation der Universität München (FIPMK), 29, 65-123.

PORTER, R. J., JR. (1986). Speech messages, modulations, and motions. Journal of Phonetics, 14, 83-88.

Scort, S., \& Howell, P. (1992). Perceptual centers in speech: An acoustic analysis [Abstract]. Journal of the Acoustical Society of America, 94 (4, Pt. 2), 2443.

SMITH, M. R., \& Fowler, C. A. (1984). The perceptual centers of alliterative monosyllables [Abstract]. Journal of the Acoustical Society of America, 76 (Suppl. 1), S81.

SUCHOWERSKYJ, W. (1977). Beurteilung kontonuierlicher Schalländerungen [A frequency analysis of acoustic continua]. Acustica, 38, 140147 .

TUller, B., \& Fowler, C. A. (1980). Some articulatory correlates of perceptual isochrony. Perception \& Psychophysics, 27, 277-283.

Tuller, B., \& Fowler, C. A. (1981). The contribution of amplitude to the perception of isochrony. In Haskins Laboratories Status Report on Speech Research (Rep. No. SR-65, pp. 245-250). New Haven, CT: Haskins Laboratories.

\section{NOTES}

1. The $10-\mathrm{msec}$ quantization was chosen because subjects reported that shorter increments were not discernible. Shorter increments did increase adjustment times, however. Also, Cooper et al. (1986) pooled data from trials in which subjects found $\mathrm{p}$-centers by a method of adjustment procedure with $1-\mathrm{msec}$ and 12.8 -msec quantization intervals, because the two sets of data were very similar.

2. All post hoc comparisons of means were made with the use of Tukey's honestly significant difference (HSD) test. The $p$ value criterion for significance was $p=.05$.

(Manuscript received April 10, 1995; revision accepted for publication April 9, 1996.) 